\title{
A utilização de antioxidantes orais na fotoproteção: revisão sistemática
}

\author{
Luma Aquino de Ávila*, Fabian Teixeira Primo
}

Universidade Católica de Pelotas, Pelotas, RS, Brasil

\author{
Histórico do Artigo: \\ Recebido em: \\ 13/12/2020 \\ Aceito em: \\ $19 / 03 / 2021$
}

\section{Palavras-chave:}

Antioxidante; radiação ultravioleta; suplementação oral; fotoproteção.

Keywords:

Antioxidant; ultraviolet radiation; oral supplementation; photoprotection.

\begin{abstract}
RESUMO
A exposição excessiva à radiação solar é um dos principais contribuintes para o desenvolvimento do câncer de pele e fotoenvelhecimento. A fotoproteção oral tem sido utilizada como uma nova estratégia para o cuidado da pele, mesmo não sendo utilizada no lugar dos filtros solares tópicos ela pode agir de forma complementar a estes. Os antioxidantes orais parecem ser bons candidatos para reduzir os danos mediados pela radiação ultravioleta e prevenir as consequências para a saúde em razão da exposição excessiva. O objetivo deste estudo é revisar sistematicamente a utilização de antioxidantes orais na fotoproteção, identificando quais os principais antioxidantes orais existentes com evidências científicas comprovadas, evidenciando o mecanismo de ação de cada um deles, bem como demonstrar os possíveis efeitos no fotoenvelhecimento e câncer de pele. Para isso foi realizada uma pesquisa nas bases de dados: Science Direct, Pubmed, Scielo e Lilacs. Os critérios utilizados para a seleção dos artigos foram: artigos científicos relacionados com a temática em estudo, artigos disponíveis integralmente na internet, estudos pré-clínico in vitro e em animais (in vivo) e estudos clínicos em humanos. Um total de 16 artigos abordaram acerca de substâncias que possuem potenciais antioxidantes e que são candidatas a fornecer os efeitos fotoprotetores contra radiação UV. No entanto, não foi verificada nenhuma substância com evidência científica comprovada, quanto ao mecanismo de ação, foram encontradas poucas evidências e essas ainda são preliminares. $E$ os efeitos antienvelhecimento e anticarcinogênico, nenhuma substância evidenciou a capacidade de atenuar estes danos.
\end{abstract}

The use of oral antioxidants in photoprotection - systematic review

\begin{abstract}
Excessive exposure to solar radiation is a major contributor to the development of skin cancer and photoaging. Oral photoprotection has been used as a new strategy for skin care, even though it is not used in place of topical sunscreens, it can act as a complement to these. Oral antioxidants appear to be good candidates for reducing damage mediated by ultraviolet radiation and preventing health consequences from overexposure. The objective of this study is to systematically review the use of oral antioxidants in photoprotection, identifying which are the main oral antioxidants with proven scientific evidence, showing the mechanism of action of each one, as well as demonstrating the possible effects on photoaging and skin cancer. For this, a search was carried out in the databases: Science Direct, Pubmed, Scielo and Lilacs. The criteria used for the selection of articles were: scientific articles related to the subject under study, articles available entirely on the internet and pre-clinical studies in vitro and in animals (in vivo) and clinical studies in humans. A total of 16 articles addressed substances that have potential antioxidants and that are candidates for providing photoprotective effects against UV radiation. However, no substance with proven scientific evidence was verified, regarding the mechanism of action, little evidence was found and these are still preliminary. And the anti-aging and anticarcinogenic effects, no substance showed the ability to mitigate these damages.
\end{abstract}

\section{Introdução}

A radiação ultravioleta do sol apresenta efeitos benéficos para a saúde humana, porém quando há uma exposição excessiva a esta radiação pode ocorrer uma variedade de efeitos negativos. Dentre eles, podemos destacar o fotoenvelhecimento e o câncer de pele (1).

A pele apesar de atuar como órgão de revestimento e proteção, não possui mecanismos suficientes para evitar os prejuízos advindos da radiação solar, exigindo a utilização de medidas fotoprotetoras adicionais, onde o protetor solar tópico se destaca como o

\footnotetext{
* Autor correspondente: lumadeavila@gmail.com (Ávila L.A.)
} 
principal método utilizado, entretanto, muitas vezes a eficácia destes é comprometida, pois ele é utilizado de forma inadequada (2). A qualidade desses fotoprotetores depende também de uma baixa hidrossolubilidade, formação de uma película ideal sobre a pele e hipoalergenicidade (3), o que muitas vezes isso não ocorre, limitando assim o seu uso.

A fotoproteção oral tem sido utilizada como uma nova estratégia para o cuidado da pele. Mesmo não sendo utilizada no lugar dos filtros solares tópicos ela pode agir de forma complementar a estes (4).

Os produtos fotoprotetores orais geralmente contêm um ou mais princípios ativos, que podem estimular diferentes mecanismos de fotoproteção, como ação anti-inflamatória, antioxidante e imunomoduladora (5). Essas substâncias atuam aumentando a eficácia antioxidante do corpo, após a perda de antioxidantes endógenos, quando há uma exposição aos raios UV (6).

Os antioxidantes orais parecem ser bons candidatos para reduzir os danos mediados pela radiação ultravioleta e prevenir as consequências para a saúde em razão da exposição excessiva (7).

O presente estudo teve como objetivo realizar uma revisão sistemática acerca da utilização de antioxidantes orais na fotoproteção, identificando quais os principais antioxidantes orais existentes com finalidade de fotoproteção, evidenciando o mecanismo de ação de cada um deles, bem como demonstrar os possíveis efeitos no fotoenvelhecimento e câncer de pele.

\section{Materiais e métodos}

A pesquisa foi realizada nas bases de dados Science Direct, US National Library of Medicine (PubMed), Scientific Electronic Library Online (Scielo) e Literatura LatinoAmericana e do Caribe em Ciências da Saúde (Lilacs), utilizando as palavras chave "antioxidant", "ultraviolet radiation", "oral supplementation", "photoprotection", sendo todas estas combinadas com o operador boleano "AND". Nos sites de busca não foram utilizados filtros, e por se tratar de um assunto recente, não foram estabelecidos limites da data de publicação dos artigos para a pesquisa. A consulta nas bases de dados foi realizada nos dias 09, 10 e 11 de setembro de 2020.

Os critérios utilizados para a seleção dos artigos foram: artigos científicos relacionados com a temática em estudo, artigos disponíveis integralmente na internet, estudos préclínico in vitro e em animais (in vivo) e estudos clínicos em humanos. Foram excluídas pesquisas não relacionadas com o tema ou que não eram o propósito da pesquisa (resultados negativos), artigos não disponíveis integralmente na internet, artigos de revisão, capítulo de livro, enciclopédia, correspondência, discussão, editorial, curta comunicação.

O processo de seleção ocorreu em cinco etapas: Primeira etapa: Artigos com títulos duplicados nas bases de dados foram excluídos. Segunda etapa: Foram eliminados artigos de revisão, capítulos de livro, enciclopédia, correspondência, discussão, editorial, curta comunicação. Terceira etapa: Leitura do título e resumo. Quarta etapa: Leitura na íntegra dos artigos selecionados. Quinta etapa: Todos os artigos selecionados que demonstraram conexão com a temática em estudo foram incluídos em uma tabela, para extrair os dados, relacionar as informações e fazer a posterior avaliação dos resultados.

\section{Resultados e Discussão}

Após a busca nos quatro bancos de dados, foram identificados um total de 256 resultados potencialmente relevantes, os quais, após exclusão daqueles em duplicata $(\mathrm{N}=38)$, 
resultaram em uma amostra composta por 218 resultados. Após a eliminação dos artigos de revisão $(\mathrm{N}=63)$, capítulos de livro $(\mathrm{N}=66)$, enciclopédia $(\mathrm{N}=7)$, correspondência $(\mathrm{N}=$ 1), discussão $(\mathrm{N}=1)$, editorial $(\mathrm{N}=4)$, curta comunicação $(\mathrm{N}=3)$, foram identificados 73 artigos de pesquisa para a leitura do título e resumo; destes, 41 foram excluídos por não estarem relacionados ao tema. Para a leitura do texto integral 32 artigos foram selecionados. Desses, 2 não se encontravam disponíveis para download e 14 não atendiam o propósito em estudo, resultando em uma amostra composta por 16 artigos.

A Figura 1 apresenta a síntese de resultados obtidos após a realização da presente Revisão Sistemática.

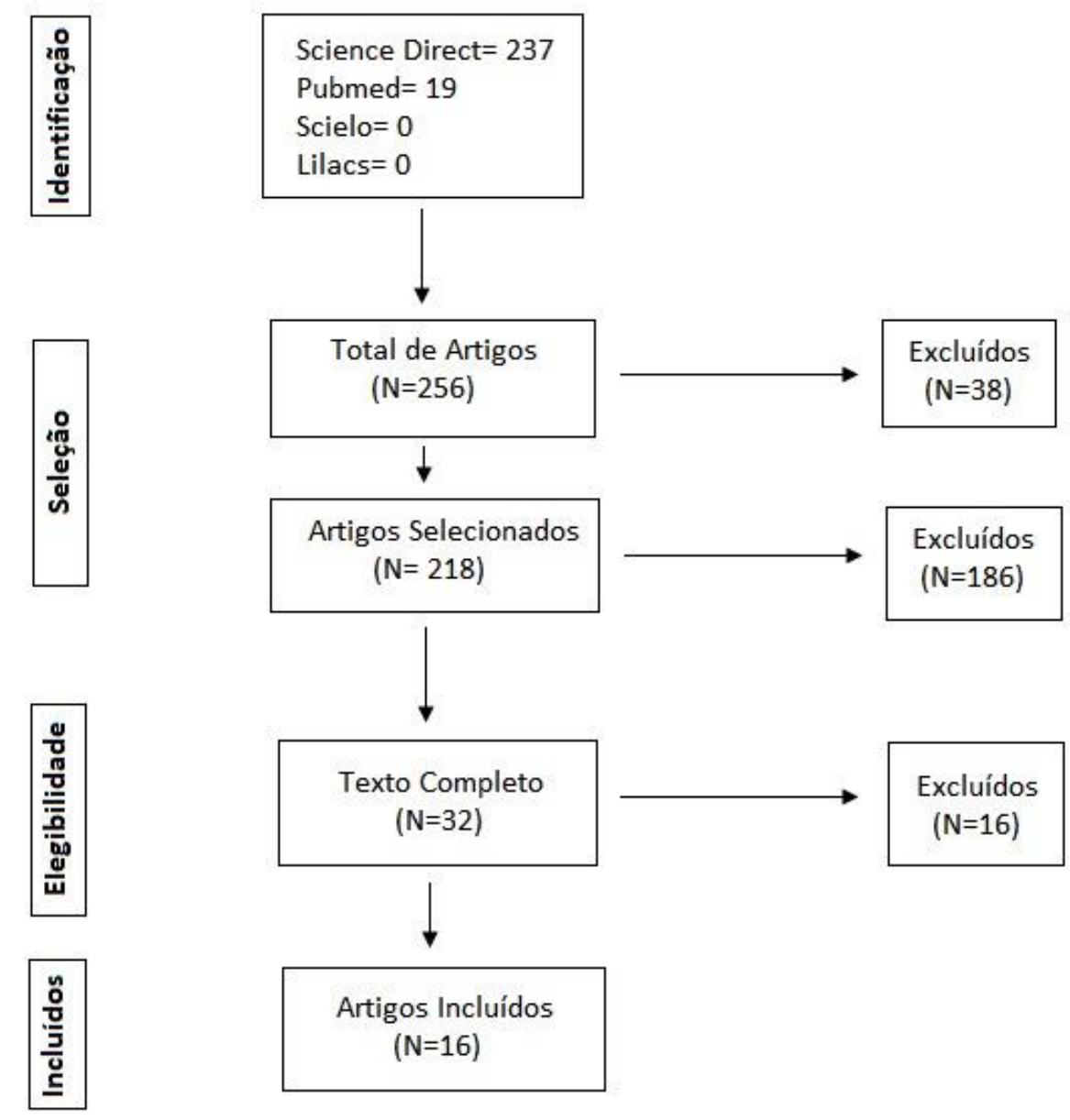

Figura 1 - Fluxograma da Revisão Sistemática 
Quadro 1 - Distribuição e caracterização dos estudos.

\begin{tabular}{|c|c|c|c|c|c|c|c|c|}
\hline Autor/Ano & Antioxidante oral & Tipo de estudo & \begin{tabular}{|c|}
$\begin{array}{c}\text { Número de } \\
\text { participantes }\end{array}$ \\
\end{tabular} & \begin{tabular}{|c|} 
Tempo \\
de suplementação
\end{tabular} & $\begin{array}{c}\text { Tipo de } \\
\text { radiaçãao }\end{array}$ & \begin{tabular}{|l|}
$\begin{array}{l}\text { Principais } \\
\text { resultados }\end{array}$ \\
\end{tabular} & $\begin{array}{c}\text { Mecanismo de } \\
\text { ação }\end{array}$ & Efeitos \\
\hline $\begin{array}{l}\text { Jeon HY, Kim } \\
\text { JK, Kim W G, } \\
\text { Lee SJ. } 2009\end{array}$ & $\begin{array}{c}\text { Galato de } \\
\text { epigalocatequina } \\
\text { (EGCG) }\end{array}$ & Estudo em animais & $\mathrm{N}=25$ ratas fêmeas & 8 semanas & UVB & $\begin{array}{c}\text { Atenuou a gravidade } \\
\text { da queimadura solar } \\
\text { e as alterações na } \\
\text { função da barreira } \\
\text { epidérmica e também } \\
\text { aumentou } \\
\text { significativamente a } \\
\text { dose eritematógena } \\
\text { mínima (DEM). }\end{array}$ & & \\
\hline $\begin{array}{l}\text { Nagapan S, Lim } \\
\text { WN, Basri DF, } \\
\text { Ghazali AR. 2019 }\end{array}$ & L-glutationa & Estudo em animais & $\begin{array}{c}\mathrm{N}=18 \\
\text { camundongos }\end{array}$ & 14 dias & UVB & \begin{tabular}{|c|} 
Inibiu a atividade da \\
melanogênese, \\
diminuindo o \\
conteúdo de \\
melanina e a \\
atividade da \\
tirosinase, reduziu o \\
estresse oxidativo, \\
aumentando os \\
níveis de \\
antioxidantes e \\
prevenindo a \\
atividade de \\
proxidação lipídica.
\end{tabular} & \begin{tabular}{|c|} 
O mecanismo da \\
ação fotoprotetora \\
poderia ser a \\
inativação direta da \\
tirosinase pela \\
ligação com o sítio \\
ativo contendo \\
cobre.
\end{tabular} & \\
\hline $\begin{array}{c}\text { Gonzalez S, Astner } \\
\text { S, An W, } \\
\text { Goukassian D, } \\
\text { Pathak MA. 2003 }\end{array}$ & $\begin{array}{c}\text { Luteína e } \\
\text { Zeaxantina }\end{array}$ & Estudo em animais & $\begin{array}{c}\mathrm{N}=25 \\
\text { camundongos }\end{array}$ & $\begin{array}{c}\text { Foram alimentados } \\
\text { em dias alternados } \\
\text { por um total de } 14 \\
\text { dias antes da } \\
\text { exposição. }\end{array}$ & UVB & \begin{tabular}{|} 
Redução no número \\
de queratinócitos, \\
diminuição do \\
número de células \\
PCNA- positivas \\
(células em \\
proliferação), \\
redução na \\
incorporação de \\
BrdU nos \\
queratinócitos \\
epidérmicos basais e \\
também suprimiu a \\
pele na inflamação.
\end{tabular} & & anticarcinogênico \\
\hline $\begin{array}{c}\text { Tao S, Park SL, } \\
\text { De La Vega MR, } \\
\text { Zhang DD, } \\
\text { Wondrak GT. } \\
2015\end{array}$ & $\begin{array}{c}\text { Bixina } \\
\text { (apocarotenóide } \\
\text { derivado do } \\
\text { licopeno) }\end{array}$ & $\begin{array}{c}\text { In vitro } \\
\text { (queratinócitos } \\
\text { humanos) } \\
\text { In vivo } \\
\text { (camundongos) }\end{array}$ & $\begin{array}{c}\mathrm{N}=24 \\
\text { camundongos }\end{array}$ & $\begin{array}{c}48 \text { horas antes da } \\
\text { exposição }\end{array}$ & $\begin{array}{l}\text { UVA e } \\
\text { UVB }\end{array}$ & \begin{tabular}{|c|} 
Na investigação em \\
camundongos a \\
bixina suprimiu o \\
fotodano da pele, \\
atenuou o dano ao \\
DNA oxidativo e \\
epidérmico e as \\
respostas \\
inflamatórias em \\
camundongos NRF2 \\
+/+, mas não em \\
camundongos NRF2 \\
-/-, mostrando a \\
dependência de \\
NRF2 na \\
citoproteção à base \\
de bixina. \\
\end{tabular} & \begin{tabular}{|c|} 
A bixina ativa o \\
NRF2, através do \\
resíduo do sensor \\
Cys-151 crítico em \\
KEAP1, \\
fornecendo uma \\
ampla resposta \\
citoprotetora em \\
queratinócitos \\
humanos em \\
cultura.
\end{tabular} & \\
\hline \begin{tabular}{|c|} 
Sánchez-Campillo \\
M, Gabaldon \\
JA, Castillo J, \\
Benavente-García \\
O, Del Baño MJ, \\
Alcaraz M et al. \\
2009 \\
\end{tabular} & $\begin{array}{c}\text { Ácido rosmarínico } \\
\text { (extraído de folhas } \\
\text { de alecrim) }\end{array}$ & \begin{tabular}{|c|} 
In vitro \\
(linfócitos \\
humanos e células \\
de camundongos) \\
In vivo \\
(camundongos) \\
\end{tabular} & $\begin{array}{c}\mathrm{N}=20 \\
\text { camundongos }\end{array}$ & 33 semanas & UVA & \begin{tabular}{|c|} 
Redução do dano à \\
pele, atividade de \\
eliminação e extinção \\
contra ERO, efeito \\
estimulador da \\
melanogênese.
\end{tabular} & & anticarcinogênico \\
\hline
\end{tabular}




\begin{tabular}{|c|c|c|c|c|c|c|c|}
\hline $\begin{array}{l}\text { Pérez-Sánchez A, } \\
\text { Barrajón-Catalán } \\
\text { E, Caturla N, } \\
\text { Castillo J, } \\
\text { Benavente-García } \\
\text { O, A lcaraz M, et } \\
\text { al. } 2014\end{array}$ & \begin{tabular}{|c|} 
Extrato de alecrim \\
e cítricos
\end{tabular} & $\begin{array}{c}\text { In vitro } \\
\text { (queratinócitos } \\
\text { humanos) } \\
\text { In vivo } \\
\text { (humanos) }\end{array}$ & $\mathrm{N}=10$ & \begin{tabular}{|c|}
8 semanas e 12 \\
semanas uma \\
proteção mais forte \\
alcançada
\end{tabular} & UVB & \begin{tabular}{|c|} 
Demonstraram \\
individualmente \\
propriedades \\
protetoras, no entanto \\
a combinação destes \\
mostrou um nível \\
mais alto de \\
proteção. A \\
combinação diminuiu \\
drasticamente a \\
geração de ERO \\
intracelulares \\
induzidos por UVB, \\
foi capaz de prevenir \\
danos ao DNA, \\
mostrou propriedades \\
genoprotetoras e \\
antimutagênicas em \\
humanos ocorreu um \\
aumento na DEM \\
após oito semanas de \\
ingestão oral, mas \\
um aumento mais \\
forte de DEM foi \\
verificado após 12 \\
semanas.
\end{tabular} & $\begin{array}{l}\text { anticarcinogênico e } \\
\text { antienvelhecimento }\end{array}$ \\
\hline $\begin{array}{c}\text { Malhomme de la } \\
\text { Roche H, } \\
\text { Seagrove S, } \\
\text { Mehta A, } \\
\text { Divekar P, } \\
\text { Campbell S, } \\
\text { Curnow A. 2010 }\end{array}$ & Chá verde & $\begin{array}{l}\text { Estudo em } \\
\text { humanos }\end{array}$ & $\mathrm{N}=10$ & $\begin{array}{c}1 \text { dose de chá } \\
\text { verde no café da } \\
\text { manhã }\end{array}$ & UVA/VIS & \begin{tabular}{|} 
Redução significativa \\
nos efeitos \\
genotóxicos \\
observados nas \\
células do sangue \\
periférico 60 minutos \\
após a ingestão.
\end{tabular} & anticarcinogênico \\
\hline $\begin{array}{c}\text { Kohli I, Shafi R, } \\
\text { Isedeh P, Griffith } \\
\text { JL, Al-Jamal MS, } \\
\text { Silpa-archa N, et } \\
\text { al. } 2017\end{array}$ & $\begin{array}{l}\text { Polypodium } \\
\text { leucotomos } \\
\text { (PL) }\end{array}$ & $\begin{array}{l}\text { Estudo em } \\
\text { humanos }\end{array}$ & $\mathrm{N}=22$ & $\begin{array}{c}1 \text { dose } 2 \text { horas e } 1 \\
\text { dose } 1 \text { hora antes } \\
\text { da irradiação }\end{array}$ & $\begin{array}{l}\text { luz visível, } \\
\text { UVA } 1 \text { e } \\
\text { UVB }\end{array}$ & \begin{tabular}{|c|} 
Resposta eritematosa \\
basal a irradiação \\
UVB nenhuma \\
resposta observada \\
após exposição a \\
UVA1. Houve um \\
aumento na DEM; \\
diminuição da \\
intensidade do \\
eritema e também \\
uma redução \\
significativa dos \\
efeitos deletérios da \\
radiação UV (danos \\
ao DNA e apoptose).
\end{tabular} & \\
\hline $\begin{array}{l}\text { Middelkamp-Hup } \\
\text { MA, Pathak MA, } \\
\text { Parrado C, } \\
\text { Goukassian D, } \\
\text { Rius-Díaz F, } \\
\text { Mihm MC, et al. } \\
2004\end{array}$ & $\begin{array}{l}\text { Polypodium } \\
\text { leucotomos } \\
\text { (PL) }\end{array}$ & $\begin{array}{l}\text { Estudo em } \\
\text { humanos }\end{array}$ & $\mathrm{N}=9$ & 2 doses & UVB & \begin{tabular}{|c|} 
Diminuição \\
significativa do \\
eritema, formação de \\
células de \\
queimaduras solar, \\
danos ao DNA, \\
hiperproliferação \\
epidérmica e \\
infiltração de \\
mastócitos dérmicos. \\
Dados histológicos \\
mostraram uma \\
tendência de \\
preservaçãa de \\
células de langerhans \\
e redução da \\
vasodilatação.
\end{tabular} & $\begin{array}{l}\text { anticarcinogênico e } \\
\text { antienvelhecimento }\end{array}$ \\
\hline $\begin{array}{c}\text { Puglia C, Offerta } \\
\text { A, Saija A, } \\
\text { Trombetta D, } \\
\text { Venera C. } 2014\end{array}$ & $\begin{array}{c}\text { Extrato de laranja } \\
\text { vermelha (Citrus } \\
\text { sinensis variedades } \\
\text { Moro, Tarocco e } \\
\text { Sanguinello). }\end{array}$ & $\begin{array}{l}\text { Estudo em } \\
\text { humanos }\end{array}$ & $\begin{array}{c}\mathrm{N}=20 \text { (avaliação } \\
\text { do eritema) } \\
\mathrm{N}=25 \text { (avaliação } \\
\text { da } \\
\text { homogeneidade) }\end{array}$ & 15 dias & UVB & \begin{tabular}{|c|} 
Reduziu \\
significativamente o \\
grau de eritema \\
cutâneo induzido por \\
UVB. Pode \\
neutralizar a \\
hiperpigmentacãa da
\end{tabular} & antienvelhecimento \\
\hline
\end{tabular}


L. A. de Ávila e F. T. Primo / Vittalle v. 33 n. 2 (2021) 97-108

\begin{tabular}{|c|c|c|c|c|c|c|c|c|}
\hline & & & & & & pele. & & \\
\hline & & & & & & & & $\begin{array}{c}\text { continua } \\
\text { continuação }\end{array}$ \\
\hline $\begin{array}{c}\text { Penna I, Albanesi } \\
\text { E, Bertorelli R, } \\
\text { Bandiera T, } \\
\text { Russo D. } 2019\end{array}$ & \begin{tabular}{|} 
Extrato de laranja \\
vermelha \\
combinada com \\
ácido hialurônico \\
(IALUTEC RED)
\end{tabular} & $\begin{array}{c}\text { In vitro } \\
\text { (fibroblastos } \\
\text { humanos) }\end{array}$ & & 24 horas & UVB & \begin{tabular}{|c|} 
Teve um efeito \\
citoprotetor, \\
diminuiu a resposta \\
inflamatória \\
reduzindo a \\
expressão das \\
citocinas pró- \\
inflamatórias IL1- $\beta$ e \\
TNF- $\alpha$, e \\
da enzima \\
antioxidante GPX1 e \\
teve a capacidade de \\
eliminar ERO. \\
\end{tabular} & & antienvelhecimento \\
\hline $\begin{array}{c}\text { Saliou C, } \\
\text { Rimbach G, } \\
\text { Moini H, } \\
\text { McLaughlin L, } \\
\text { Hosseini S, Lee J, } \\
\text { et al. } 2001\end{array}$ & Pycnogenol (PBE) & $\begin{array}{c}\text { In vitro } \\
\text { (queratinócitos } \\
\text { humanos) } \\
\text { In vivo } \\
\text { (humanos) }\end{array}$ & $\mathrm{N}=21$ indivíduos & $\begin{array}{l}\text { Duas fases de } \\
\text { tratamento de } 4 \\
\text { semanas }\end{array}$ & $\begin{array}{l}\text { UVA e } \\
\text { UVB }\end{array}$ & \begin{tabular}{|c|} 
Um aumento na \\
DEM foi observado \\
após a suplementação \\
nas 4 primeiras \\
semanas e nas \\
últimas 4 semanas do \\
estudo causaram um \\
aumento ainda maior \\
na DEM. \\
\end{tabular} & $\begin{array}{c}\text { Inibição da } \\
\text { expressão do gene } \\
\text { dependente de NF- } \\
\text { kB induzida por } \\
\text { UV, uma etapa } \\
\text { importante na } \\
\text { reação } \\
\text { inflamatória. } \\
\end{array}$ & \\
\hline \begin{tabular}{|c|} 
Grether-Beck S, \\
Marini A, Jaenicke \\
T, Stahl W, \\
Krutmann J. 2017
\end{tabular} & $\begin{array}{l}\text { Licopeno (TNC) e } \\
\text { Luteína }\end{array}$ & $\begin{array}{c}\text { Estudo de } \\
\text { intervenção } \\
\text { cruzado } \\
\text { randomizado, } \\
\text { duplo-cego } \\
\text { controlado por } \\
\text { placebo }\end{array}$ & $\mathrm{N}=65$ & $\begin{array}{l}\text { Duas fases de } \\
\text { tratamento } \\
\text { de } 12 \text { semanas }\end{array}$ & $\begin{array}{l}\text { UVA / B - e } \\
\text { UVA1 }\end{array}$ & \begin{tabular}{|c|} 
TNC inibiu \\
completamente a \\
UVA1, bem a \\
suprarregulação \\
induzida por UVA /B \\
de mRNA de HO-1, \\
ICAM-1 e MMP1, \\
independentemente \\
da sequência. Em \\
contraste, a luteína \\
forneceu proteção \\
completa se for \\
tomada no primeiro \\
período, mas mostrou \\
efeitos \\
significativamente \\
menores na segunda \\
sequência em \\
comparação com o \\
licopeno. \\
\end{tabular} & & $\begin{array}{l}\text { anticarcinogênse e } \\
\text { antienvelhecimento }\end{array}$ \\
\hline $\begin{array}{c}\text { Marini A, Jaenicke } \\
\text { T,Grether-Beck S, } \\
\text { Le Floc'h C, } \\
\text { Cheniti A, Piccardi } \\
\text { N, et al. } 2014\end{array}$ & $\begin{array}{l}\text { Licopeno, } \beta- \\
\text { caroteno, e } \\
\text { lactobacillus } \\
\text { johnsonii }\end{array}$ & $\begin{array}{c}\text { Estudo } \\
\text { randomizado, } \\
\text { duplo-cego, } \\
\text { controlado por } \\
\text { placebo }\end{array}$ & $\mathrm{N}=60$ & 12 semanas & UVA 1 & \begin{tabular}{|c|} 
A nível molecular, o \\
desenvolvimento de \\
lesões cutâneas foi \\
associado a um \\
aumento da \\
expressão de ICAM- \\
1 mRNA que foi \\
significativamente \\
reduzido após a \\
suplementação, mas \\
não com placebo. \\
Porém, não foi \\
detectado uma \\
redução significativa \\
nas pontuações de \\
EPL dos pacientes \\
tratados após uma \\
segunda exposicão.
\end{tabular} & & \\
\hline $\begin{array}{c}\text { Egoumenides L, } \\
\text { Gauthier A, Barial } \\
\text { S, Saby M, } \\
\text { Orechenkoff C, } \\
\text { Simoneau G, et al. } \\
2018\end{array}$ & $\begin{array}{l}\text { Concentrado de } \\
\text { melão }\end{array}$ & $\begin{array}{c}\text { Estudo clínico } \\
\text { controlado vs. } \\
\text { placebo, } \\
\text { randomizado, } \\
\text { duplo cego }\end{array}$ & $\mathrm{N}=88$ & 32 dias & $\begin{array}{l}\text { UVA e } \\
\text { UVB }\end{array}$ & \begin{tabular}{|c|} 
Aumento \\
significativo da DEM \\
após o concentrado \\
de melão aplicado \\
topicamente e \\
suplementado via \\
oral em comparação \\
ao grupo placebo e \\
este aumento foi \\
obtido após um \\
período maior de \\
suplementação. \\
\end{tabular} & & \\
\hline
\end{tabular}




\begin{tabular}{|c|c|c|c|c|c|c|c|}
\hline $\begin{array}{c}\text { Greul AK, } \\
\text { Grundmann JU, } \\
\text { Heinrich F, } \\
\text { Pfitzner I, } \\
\text { Bernhardt J, } \\
\text { Ambach A, et al. } \\
2002\end{array}$ & \begin{tabular}{|c|} 
Seresis $®$, uma \\
combinação de \\
antioxidantes \\
contendo lipídios e \\
compostos \\
solúveis em água: \\
carotenoides \\
(ßcaroteno e \\
licopeno), \\
vitaminas C e E, \\
selênio e \\
proantocianidinas.
\end{tabular} & $\begin{array}{l}\text { Estudo clínico, } \\
\text { randomizado, } \\
\text { duplo-cego, de } \\
\text { grupo paralelo e } \\
\text { controlado por } \\
\text { placebo }\end{array}$ & $\mathrm{N}=48$ & 12 semanas & UVB & $\begin{array}{c}\text { Não mostrou } \\
\text { diferenças } \\
\text { significativas na } \\
\text { DEM em } \\
\text { comparação com o } \\
\text { placebo, mas } \\
\text { forneceu uma } \\
\text { diminuição } \\
\text { significativa da } \\
\text { MMP-1 } \\
\text { (metaloproteinases). }\end{array}$ & antienvelhecimento \\
\hline
\end{tabular}

Após pesquisa, foram encontrados dezesseis artigos que abordavam acerca de substâncias que possuem potenciais antioxidantes e que são candidatas a fornecer os efeitos fotoprotetores contra a radiação ultravioleta (Quadro 1).

Nestes artigos, algumas substâncias foram estudadas de forma individual e outras de forma combinada. Entre essas substâncias estão: o galato de epigalocatequina (EGCG) (8), a L-glutationa (9), a luteína e a zeaxantina (10), a bixina (apocarotenóide derivado do licopeno) (11), o ácido rosmarínico (extrato de folhas de alecrim) (12), extratos de alecrim e cítricos (13), o chá verde (14), dois estudos abordaram sobre o polypodium leucotomos (PL) $(15,16)$, o extrato de laranja vermelha (Citrus sinensis variedades Moro, Tarocco e Sanguinello) (17), extrato de laranja vermelha combinada com o ácido hialurônico (IALUTEC RED) (18), o pycnogenol (PBE) (19), o licopeno (TNC) e a luteína (20), o licopeno, $\beta$ - caroteno e o lactobacillus johnsonii (21), o concentrado de melão (22) e o Seresis que é uma combinação de antioxidantes contendo lipídios e compostos solúveis em agua: carotenóides ( $\beta$ - caroteno e licopeno), vitaminas $\mathrm{C}$ e E, selênio e proantocianidinas (23).

Nos estudos do galato de epigalocatequina (EGCG) que é uma das catequinas que estão presentes em quantidades consideráveis no chá verde, da L-glutationa e luteína e zeaxantina, pode-se observar que estes têm a capacidade de atenuar contra a radiação UVB. Os resultados obtidos do EGCG após a ingestão regular de 8 semanas, da Lglutationa por 14 dias e da luteína e zeaxantina por um total de 14 dias também, sugerem serem bons candidatos na fotoproteção sistêmica $(8,9,10)$.

No entanto, estes estudos ainda se encontram na fase de estudos pré-clínicos em animais, sendo necessário ser realizados estudos clínicos para atingir uma evidência científica maior e confirmar efetivamente a eficácia que está sendo apresentada como promissora nestes estudos pré-clínicos. Além disso, o estudo da luteína e zeaxantina é um dos primeiros estudos em animais a nível celular cutâneo que avaliam os efeitos protetores desta ingestão. Embora, a luteína seja uma substância que já foi estudada com outros compostos, inclusive em ensaios randomizados e demonstrou evidências de efeitos fotoprotetores, porém sua combinação com a zeaxantina ainda carece de estudos mais aprofundados.

Os estudos da bixina demonstraram que esta é um ativador dependente da resposta citoprotetora orquestrada por NRF2 (fator de transcrição sensível ao redox que orquestra os principais mecanismos de defesa celular), em cultura de queratinócitos de pele humana e também evidenciaram fotoproteção da pele contra UVA e UVB, dependente de NRF2 por administração sistêmica de bixina, 48 horas antes da exposição UV em camundongos (11). Porém, por estar em fase inicial de análises, são necessários estudos clínicos para explorar este potencial e efetivamente confirmar esta eficácia fotoprotetora.

Sánchez-Campillo e colaboradores (12), realizaram estudos in vitro e in vivo (camundongos), onde sugerem que o dano à pele pela geração de espécies reativas de 
oxigênio (ERO) induzida por UVA é reduzido pela suplementação oral de ácido rosmarínico (extraído das folhas de alecrim), após 33 semanas. Apresentando, boas perspectivas de avanços de estudos de sua atividade de forma sinérgica e também estudos em modelo de tratamento sistemático in vivo.

No estudo dos extratos de alecrim e cítricos (13), indicou que estes agindo de forma sinérgica proporciona efeitos protetores mais fortes em comparação com os extratos utilizados de forma individual contra radiação UVB e, quando as propriedades fotoprotetoras desta combinação foram corroboradas em voluntários humanos, houve um aumento significativo na dose eritematógena mínima (DEM) após oito semanas de ingestão oral. Mas, um aumento mais forte de DEM, foi verificado após 12 semanas.

Sendo assim, a pesquisa dos extratos de alecrim e cítricos confirmou os estudos promissores do ácido rosmarínico, estimando uma confiança melhor nos efeitos propostos, indicando que estes podem atenuar contra as radiações UVA e UVB, no entanto, esta pesquisa foi realizada pela primeira vez $(12,13)$.

As análises realizadas de forma individual, com o chá verde, polypodium leucotomos e extrato de laranja vermelha, já apontam evidências de fotoproteção em estudos clínicos em humanos $(14,15,16,17)$. O estudo do chá verde demonstrou potencial de proteção genotóxica à radiação UVA/VIS, após a ingestão de três xícaras de chá verde no café da manhã, porém, trata-se de um pequeno estudo conduzido em apenas dez voluntários humanos saudáveis (14).

Outros dois estudos avaliaram a ingestão oral de polypodium leucotomos (PL). Kohli e colaboradores (15), sugerem que o PL pode ser potencialmente usado como um agente adjuvante para diminuir os efeitos biológicos negativos da radiação UVB, porém, nenhuma resposta foi observada quando expostos à radiação UVA1, após a ingestão duas horas e uma hora antes da irradiação. Entretanto, neste estudo o número de participantes envolvidos foram de vinte e dois indivíduos.

Middelkamp-Hup e colaboradores (16), apontam que administração de duas doses (a primeira na noite anterior à segunda exposição, e a outra no dia seguinte) levou a uma proteção significativa da pele contra radiação UVB. Este estudo envolveu um total de nove participantes saudáveis.

Nos dois estudos do extrato de laranja vermelha (variedades Moro, Tarocco e Sanguinello), evidenciaram efeitos fotoprotetores desta substância contra a irradiação UVB $(17,18)$. O estudo do extrato de laranja vermelha individualmente foi avaliado, vinte voluntários demonstraram uma redução significativa do grau de eritema cutâneo e outros vinte e cinco participaram do experimento determinando que a ingestão de laranja vermelha pode neutralizar a hiperpigmentação cutânea, após uma suplementação por 15 dias (17). Já no estudo da laranja vermelha de forma combinada com o ácido hialurônico (IALUTEC RED), foi avaliada somente em fibroblastos humanos (18). Sendo necessário mais pesquisas para avaliar os efeitos desta substância de forma combinada, em estudos de fase pré-clínica em animais e clínica.

E também o estudo com pycnogenol (PBE) (19), evidenciou os resultados na linha celular de queratinócitos humanos HaCaT e em voluntários humanos, resultando em uma eficácia contra os efeitos deletérios da irradiação UVA e UVB, após duas fases de tratamento de quatro semanas, porém os resultados evidenciados foram em uma amostragem de vinte e um voluntários.

De todos os artigos, apenas quatro são estudos clínicos randomizados $(20,21,22,23)$. No estudo envolvendo o complexo de nutrientes de tomate rico em licopeno (TNC) e cápsulas contendo luteína, ocorreu em duas fases de tratamento de 12 semanas, onde o TNC inibiu completamente a UVA1, bem como a suprarregulação induzida por UVA/B de mRNA de HO-1 (heme oxigenase-1), ICAM-1 (molécula de adesão intercelular -1) e MMP-1 
(metaloproteinase-1 de matriz), independente da sequência. Em contraste, a luteína forneceu proteção completa quando tomada no primeiro período, mas mostrou efeitos significativamente menores na segunda sequência em comparação com o TNC (20).

Esses resultados são similares aos do estudo da suplementação oral do complexo nutricional contendo os antioxidantes licopeno e $\beta$ - caroteno, bem como o probiótico específico lactobacillus johnsonii onde o desenvolvimento de lesões cutâneas principalmente a erupção polimórfica à luz (EPL) induzidas antes da suplementação pela radiação UVA1, foi associado a um aumento da expressão de ICAM- 1 mRNA, que foi significativamente reduzido após a suplementação de 12 semanas, mas não com placebo. Porém, neste estudo foi apontado que o suplemento fornece uma fotoproteção parcial, pois, não foi detectado uma redução significativa nas pontuações de EPL dos pacientes tratados após uma segunda exposição a UVA1 (21).

$\mathrm{O}$ estudo do concentrado de melão demonstrou que tem a capacidade de atuar contra UVA e UVB. Os resultados mostram que quando o creme ativo e o suplemento ativo de concentrado de melão foram usados em combinação, houve uma tendência de que a DEM aumentou ainda melhor do que com os produtos usados isoladamente, sendo esse aumento obtido após um período maior de suplementação (22).

Em contraste, o seresis que é uma combinação de antioxidantes contendo lipídios e compostos solúveis em água: carotenóides ( $\beta$ - caroteno e licopeno), vitaminas $\mathrm{C}$ e $\mathrm{E}$, selênio e proantocianidinas, não mostrou diferenças significativas na DEM em comparação com o placebo, mas suprimiu os efeitos dérmicos induzidos por UVB ao diminuir a MMP-1, após um período de 12 semanas de suplementação (23), havendo uma semelhança com o licopeno e a luteína.

Dentre estes estudos, o número de participantes foram de: concentrado de melão $(n=88)$, seresis $(n=48)$ e o licopeno e luteína $(n=65)$, sendo analisados majoritariamente indivíduos sadios, já no estudo do complexo nutricional, 60 pacientes com EPL foram suplementados, indicando que este estudo não se restringe somente a humanos saudáveis, mas pode ser estendido a indivíduos que sofrem de fotodermatose, como EPL. Entretanto este estudo foi realizado pela primeira vez $(20,21,22,23)$.

Quanto ao mecanismo de ação destas substâncias, os dados do estudo da bixina demonstraram a viabilidade de se obter fotoproteção cutânea dependente de NRF2. A bixina ativa o NRF2, através do resíduo do sensor Cys-151 crítico em KEAP1, fornecendo uma ampla resposta citoprotetora em queratinócitos humanos em cultura (11).

No estudo do pycnogenol, o mecanismo de ação foi proposto pela inibição da expressão do gene dependente de NF-kB induzida por UV, uma etapa importante na reação inflamatória, em cultura de células de queratinócitos. A inibição do gene dependente de NF-kB por PBE possivelmente contribui para o aumento observado na DEM, que foi relatado anteriormente (19). Mas por serem dois estudos preliminares, possuem evidência limitada e carecem de mais pesquisas para verificar a pertinência desses mecanismos de ação.

Já a L-glutationa diminuiu o nível da enzima tirosinase, mostrando que o mecanismo da ação fotoprotetora da L-glutationa poderia ser a inativação direta da tirosinase pela ligação com o sítio ativo contendo cobre (9); mas, somente sugeriu não realizou estudos para evidenciar.

Dentre todos os estudos analisados, nove mencionam sobre os efeitos antienvelhecimento e anticarcinogênico $(10,12,13,14,16,17,18,20,23)$. Sendo que oito artigos, apenas sugerem ter algum destes efeitos $(10,13,14,16,17,18,20,23)$. Destes, dois possuem evidências com potenciais anticarcinogênicas $(14,10)$. O chá verde sugere investigações de uso crônico desta substância para resultar em um grau de proteção que possa prevenir ou reduzir a carcinogênese cutânea (14). A luteína e zeaxantina dietéticas mostram que os efeitos inibitórios na inflamação aguda e hiperproliferação 
epidérmica pode ter uma implicação potencial para a prevenção da carcinogênese em pele cronicamente exposta a UV (10).

Outros três, têm potenciais no fotoenvelhecimento $(17,18,23)$. Há hipóteses de que a ingestão de extrato de laranja vermelha individualmente, pode fortalecer as defesas antioxidantes fisiológicas da pele protegendo-a dos processos prejudiciais envolvidos no fotoenvelhecimento e levando a uma melhora na pele e pigmentação (17). No estudo do extrato de laranja vermelha combinado com ácido hialurônico atuam na diminuição da resposta inflamatória e geração de ERO, sugerindo que estes dois eventos estão envolvidos no fotoenvelhecimento, reduzindo assim este dano (18). E o seresis por ter a capacidade de suprimir os efeitos dérmicos, diminuindo a MMP-1, isto pode ser de grande importância para o fotoenvelhecimento prematuro, que é induzido por regulação positiva crônica de enzimas que degradam a matriz (23).

Por último, três podem contribuir para essas duas patologias $(16,20,13)$. A PL aponta que os resultados obtidos como a diminuição significativa do eritema, formação de células de queimaduras solar, danos ao DNA, hiperproliferação epidérmica de curto prazo são promissores, sugerindo que esta pode ser capaz de proteger contra danos à pele, como câncer de pele induzidos por UV em longo prazo, e que a capacidade de diminuir a infiltração de mastócitos dérmicos pode levar a redução do fotoenvelhecimento (16). Sugere-se uma eficiência do licopeno e luteína no fotoenvelhecimento e fotocarcinogênese, pois inibem as respostas do estresse oxidativo induzida pela radiação UVA1 em geral e os eventos reguladores de genes envolvidos nessas patologias (20). E os extratos de alecrim e cítricos sugerem perante as evidências, ou seja, aumento da sobrevivência celular e a diminuição da geração de ERO intracelular e danos ao DNA que os extratos combinados podem ser capaz de atenuar fotoenvelhecimento e câncer de pele (13).

Em apenas um, foi realizado experimentos avaliando os efeitos fotoprotetores contra a fotocarcinogênese e o antienvelhecimento. Foi estudada a capacidade do ácido rosmarínico em inibir essas alterações, todos os animais que foram tratados por via oral com AR apresentaram apenas displasia leve em 30\% dos casos, indicando assim uma ação fotoprotetora contra essas lesões causadas por UVA (12).

Sendo assim, estes artigos demonstram que estas substâncias possuem potenciais antioxidantes na fotoproteção, no entanto, muitas delas oferecem confiança moderada nos efeitos estimados, por serem estudos muito recentes, ainda carecem de um desenvolvimento melhor das análises para confirmar a qualidade das evidências, algumas substâncias ainda estão em fase de ensaios pré-clínicos $(8,9,10,11,12,18)$ e outras indicam avanços da fase pré-clínica para a fase clínica, porém ainda são preliminares (13).

No entanto, nos estudos clínicos realizados em humanos (14, 15, 16, 17, 19), já demonstram que as substâncias possuem boas perspectivas, pois os estudos já estão em uma fase mais avançada, entretanto, são necessárias pesquisas mais amplas, com número de participantes o suficiente para dar uma resposta mais confiável às questões investigadas e para que possa fornecer uma confiança mais forte nos efeitos fotoprotetores. Entretanto, os estudos clínicos randomizados (20, 21, 22, 23), indicaram ação fotoprotetora das substâncias, mesmo ocorrendo algumas limitações nos seus efeitos fotoprotetores. Porém indicam estar na fase inicial dos ensaios clínicos, pois o número de participantes envolvidos nestes estudos ainda são pequenos, e também o complexo nutricional relata ser um estudo preliminar. Necessitando assim, de estudos maiores para evidenciar com mais precisão esses achados.

Além disso, observou-se que a maioria dos estudos relataram que é necessário tratamentos a longo prazo para obter os resultados desejados $(8,9,10,12,13,17,19,20$, $21,22,23)$. No entanto, no estudo pré-clínico da bixina em camundongos o efeito se deu 
em apenas uma dose (11), no estudo do chá verde (14) também em apenas uma dose, e nos dois estudos do polypodium leucotomos $(15,16)$, foram administradas duas doses e já possuem ação de proteção contra danos causados pelos raios solares. Portanto, o tempo de suplementação para atingir um efeito fotoprotetor, ainda precisa ser investigado por cada substância individualmente.

Sobre o mecanismo de ação em apenas dois artigos foram explorados o mecanismo molecular na fotoproteção sistêmica $(11,19)$, em apenas um, foi sugerido o mecanismo (9). Para a ação destas substâncias no antienvelhecimento e anti carcinogênese, são necessários mais estudos para validar os efeitos terapêuticos e preventivos destes produtos.

\section{Considerações finais}

São muitos os estudos prospectivos e poucos os estudos controlados que demonstraram conclusivamente os efeitos da suplementação desses antioxidantes. Sendo assim, não foi verificada nenhuma substância com evidência científica comprovada, sendo necessário o estabelecimento de padrões mais fortes para permitir uma avaliação rigorosa da eficácia dessas substâncias na fotoproteção oral.

Assim como sobre o mecanismo de ação, foram encontradas poucas evidências e essas ainda são preliminares. $E$ os efeitos antienvelhecimento e anticarcinogênico, muitos estudos correlacionaram de forma positiva a utilização destas substâncias, mas nenhum evidenciou a capacidade de atenuar estes danos.

Finalizando essa etapa da pesquisa, verificou-se que esses resultados servem de um bom ponto de partida para acelerar o desenvolvimento dos estudos dessas substâncias antioxidantes com ação fotoprotetora, fornecendo evidências científicas dos benefícios do uso da suplementação oral na proteção cutânea contra as radiações ultravioleta, que podem ser utilizados de forma sinérgica ao protetor tópico garantindo maior eficiência na proteção.

\section{Referências}

1. Balogh TS, Velasco MVR, Pedriali CA, Kaneko TM, Baby AR. Proteção à radiação ultravioleta: Recursos disponíveis na atualidade em fotoproteção. An Bras Dermatol. 2011;86(4): 732-742.

2. Santos LG dos, Rocha MS da. O uso de antioxidantes orais na fotoproteção. Rev Acadêmica Oswaldo Cruz. 2016; 11:1-8.

3. Tofetti MH de FC, Oliveira VR. A importância do uso do filtro solar na prevenção do fotoenvelhecimento e do câncer de pele. Investig - Rev Científica da Univ Fr. 2006; 6(1) :59-66.

4. Gonzalez S, Gilabert Y, Philips N, Juarranz A. Current Trends in Photoprotection - A New Generation of Oral Photoprotectors. Open Dermatol J. 2011;5(1): 6-14.

5. Noronha MDM de. Tendências mais recentes na fotoproteção [Tese]. Lisboa: Farm Univ Lusófona Humanidades e Tecnol Lisboa; 2014.

6. Parrado C, Philips N, Gilaberte Y, Juarranz A, González S. Oral photoprotection: Effective agents and potential candidates. Front Med 2018; 5:1-19.

7. Guaratini T, Medeiros MHG, Colepicolo P. Antioxidantes na manutenção do equilíbrio redox cutâneo: Uso e avaliação de sua eficácia. Quim Nova. 2007; 30(1): 206-213.

8. Jeon HY, Kim JK, Kim WG, Lee SJ. Effects of oral epigallocatechin gallate supplementation on the minimal erythema dose and uv-induced skin damage. Skin Pharmacol Physiol. 2009; 22(3): 137-141.

9. Nagapan TS, Lim WN, Basri DF, Ghazali AR. Oral supplementation of L-glutathione prevents ultraviolet B-induced melanogenesis and oxidative stress in BALB/c mice. Exp Anim. 2019; 68(4): 541-548.

10. Gonzalez S, Astner S, An W, Goukassian D, Pathak MA. Dietary Lutein/Zeaxanthin Decreases Ultraviolet B-Induced Epidermal Hyperproliferation and Acute Inflammation in Hairless Mice. J Invest Dermatol. 2003; 121: 399-405.

11. Tao S, Park SL, De La Vega MR, Zhang DD, Wondrak GT. Systemic administration of the 
apocarotenoid bixin protects skin against solar UV-induced damage through activation of NRF2. Free Radic Biol Med. 2015; 89: 690-700.

12. Sánchez-Campillo M, Gabaldon JA, Castillo J, Benavente-García O, Del Baño MJ, Alcaraz M, et al. Rosmarinic acid, a photo-protective agent against UV and other ionizing radiations. Food Chem Toxicol. 2009; 47(2): 386-392.

13. Pérez-Sánchez A, Barrajón-Catalán E, Caturla N, Castillo J, Benavente-García O, Alcaraz M, et al. Protective effects of citrus and rosemary extracts on UV-induced damage in skin cell model and human volunteers. J Photochem Photobiol B Biol. 2014; 136: 12-18.

14. Malhomme de la Roche H, Seagrove S, Mehta A, Divekar P, Campbell S, Curnow A. Using natural dietary sources of antioxidants to protect against ultraviolet and visible radiation-induced DNA damage: An investigation of human green tea ingestion. J Photochem Photobiol B Biol. 2010; 101(2): 169-173.

15. Kohli I, Shafi R, Isedeh P, Griffith JL, Al-Jamal MS, Silpa-archa N, et al. The impact of oral Polypodium leucotomos extract on ultraviolet B response: A human clinical study. J Am Acad Dermatol. 2017; 77(1): 33-41.

16. Middelkamp-Hup MA, Pathak MA, Parrado C, Goukassian D, Rius-Díaz F, Mihm MC, et al. Oral Polypodium leucotomos extract decreases ultraviolet-induced damage of human skin. J Am Acad Dermatol. 2004; 51(6): 910-918.

17. Puglia C, Offerta A, Saija A, Trombetta D, Venera C. Protective effect of red orange extract supplementation against UV-induced skin damages: Photoaging and solar lentigines. J Cosmet Dermatol. 2014; 13: 151-157.

18. Penna I, Albanesi E, Bertorelli R, Bandiera T, Russo D. Cytoprotective, anti-inflammatory, and antioxidant properties of high-molecular-weight hyaluronan enriched with red orange extract in human fibroblasts exposed to ultra violet light B irradiation. Biotechnology and Applied Biochemistry. 2019; 66(3): 273-280

19. Saliou C, Rimbach G, Moini H, McLaughlin L, Hosseini S, Lee J, et al. Solar ultraviolet-induced erythema in human skin and nuclear factor-kappa-B-dependent gene expression in keratinocytes are modulated by a French maritime pine bark extract. Free Radic Biol Med. 2001; 30(2): 154-160.

20. Grether-Beck S, Marini A, Jaenicke T, Stahl W, Krutmann J. Molecular evidence that oral supplementation with lycopene or lutein protects human skin against ultraviolet radiation: results from a double-blinded, placebo-controlled, crossover study. Br J Dermatol. 2017; 176(5): 1231-1240.

21. Marini A, Jaenicke T, Grether-Beck S, Le Floc'h C, Cheniti A, Piccardi N, et al. Prevention of polymorphic light eruption by oral administration of a nutritional supplement containing lycopene, $\beta$ carotene, and Lactobacillus johnsonii: Results from a randomized, placebo-controlled, double-blinded study. Photodermatol Photoimmunol Photomed. 2014; 30(4): 189-194.

22. Egoumenides L, Gauthier A, Barial S, Saby M, Orechenkoff C, Simoneau G, et al. A specific melon concentrate exhibits photoprotective effects from antioxidant activity in healthy adults. Nutrients. 2018; 10:1-15.

23. Greul AK, Grundmann JU, Heinrich F, Pfitzner I, Bernhardt J, Ambach A, et al. Photoprotection of UV-irradiated human skin: An antioxidative combination of vitamins $\mathrm{E}$ and $\mathrm{C}$, carotenoids, selenium and proanthocyanidins. Skin Pharmacol Appl Skin Physiol. 2002; 15:307-315. 